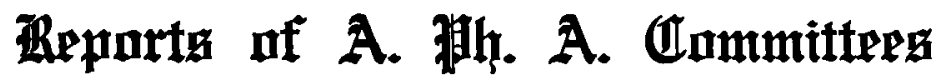

\section{REPORT OF COMMITTEE ON UNOFFICIAL STANDARDS.}

GEO. M. BERINGER, PH. M., CAMDEN, N. J., CHAIRMAN.

During the past year there was prepared a list of the articles entering into the formulas that had been admitted in the revision of the National Formulary. As the work on the revision of the National Formulary has progressed, several such lists were submitted by members of that committee, but they were necessarily incomplete. After the Boston meeting, the scope of the N. F. IV could be considered as practically established so far as additions and deletions and the tentative formulas for the new preparations. A review of the entire correspondence on the National Formulary in the Bulletin of the American Pharmaceutical Association and the circular letters of the Committee was necessary in order to compile a list that would exhibit the work still required of the Committee on Unofficial Standards in their assigned duty to cooperate with the National Formulary committee in the establishing of standards for the non-pharmacopœial articles used in the Formulary.

On the basis of this compilation, the new assignment of subjects to the individual members of our Committee for special study and report was made. The work accomplished in the past year of the Association is, in part, represented by the forty-five monographs that have been approved by the Committee and which are presented herewith for publication. There are still a number of reports before the Committee on which the discussions have not yet progressed to a conclusion. In addition, a number of the assigned subjects are still under study by the referees.

The work accomplished has not measured up to our anticipation, and it is but fair to the members to offer in extenuation some explanation.

A study of the reports submitted by this Committee will exhibit the wide range of subjects that have to be considered, coming from all quarters of the globe, and from the animal, vegetable and mineral kingdoms. For some of these articles, authoritative statements may be found in the foreign pharmacopœias, which, after confirmation by a referee, may serve as the basis for our standards. However, many more of the articles that we have to consider are not mentioned in any of the pharmacopœias and the work on standards for such must be largely based upon examination of the commercial products used. These require much study, investigation and experimentation.

. It is probable that in the desire for accuracy, the referees have, in many cases. gone into details and extensive studies that may not be considered necessary for 
our work, but just such conscientious labor is required if the standards that we propose are to be adopted and become the legal authority.

The members of this Committee are all actively engaged in other duties, and so can spare but a portion of their time to the assignments in connection with this work. Ten of our members have been drafted into the Conmittee of Revision of the United States Pharmacopoia and four of these are chairmen of important sub-committees and members of the Executive Committee of the Committee of Revision. Hence, it will be understood how these other demands on time and energy have interfered with the anticipated progress in the establishing of standards for non-pharmacopoial articles. Nevertheless, we hope that the special work relating to the National Formulary standards may be completed by the time such will be needed for the publication of the revised edition of the Formulary.

As the scope of the U. S. P. IX was gradually decided upon, it became more and more apparent that a number of the articles our Committee had under consideration, and for some of which we had already adopted standards, would be included in the Pharmacopœia. By a happy coincidence, much of this work in the pharmacopœial revision fell upon members of our Committee who had already considered these topics, and thus their previous labors will aid in expediting the revision of the Pharmacopoia. This is but another illustration of the close relationship that exists between the work of the Pharmacopœial Revision Committee, the Committee on National Formulary and the Committee on Unofficial Standards, and emphasizes the necessity for cooperation of these several committees and the need for harmonizing the standards that each establishes.

The terms of the following members expire this year by limitation: Henry Kraemer, Eustace H. Gane, B. L. Murray and W. A. Puckner, and it is incumbent upon the Council to elect their successors. Changes in the personnel of the Committee should be avoided, as each change causes interruption and delay in the progress of the work, and, unless necessary, change is undesirable. The Council must likewise designate the chairman for the ensuing year.

If it be the desire of the Council that this Committee be continued, then sufficient appropriation must be made to meet the expenses of the coming year, and I recommend that a sum of $\$ 250.00$ be placed at the command of the Committee on Standards for Unofficial Drugs, Pharmaceutical Preparation and Chemical Products to meet the expenses necessitated by their work.

\section{APPROVED MONOGRAPHS SUBMITTED AS STANDARDS FOR UN- OFFICIAL DRUGS AND CHEMICAL PRODUCTS.}

The following portion of the report of the Committee on Unofficial Standards relates to certain crude drugs and chemicals suggested for inclusion in the next revision of the National Formulary, and by order of the Council is published in the Journal in order to afford opportunity for discussion before the standards proposed are finally adopted.

Manufacturers, importers, analysts, and others interested in any of the proposed 
standards, are requested to send their criticisms and comments to the chairman of the committee, Geo. M. Beringer, 501 Federal St., Camden, N. J.

\section{ALETRIS.}

True Unicorn Root, Colic Root, Star Grass.

1. The dried rhizome and roots of Aletris farinosa L. (Fam. Liliaceae). Rhizome horizontal or slightly oblique, nearly cylindrical or laterally compressed above, from 2 to 4 $\mathrm{cm}$. in length, 5 to $12 \mathrm{~mm}$. in diameter; externally grayish brown, upper portion with circular stem scars from 3 to $7 \mathrm{~mm}$. in diameter and with numerous leaf bases, the sides and lower portion with numerous tough, wiry, whitish or reddish brown roots which are more or less flexuose and provided with short branches; fracture short; internally light brown, cortex 1 to $2 \mathrm{~mm}$. thick, central cylinder with numerous circular twisted and branching fibrovascular bundles; odor slight, acetous; taste sweetish, somewhat bitter.

2. Microscopic Examination.-The greater part of the drug consists of parenchyma cells which are filled with spherical or ellipsoidal starch grains, varying from 8 to 16 microns in diameter. Some of the parenchyma cells contain raphides, the latter being from 25 to 45 microns in length. The tracheæ are reticulate or provided with simple pores and around these are several layers of lignified cells with thick walls and simple large oblique pores. The endodermis is composed of several layers of thick walled and closely lamellated cells of a deep yellow color and the cortex is readily separated.

\section{AMMONIACUM.}

Ammoniac.

1. The air dried gum resinous exudation from the stems of Dorema Ammoniacum Don. (Fam. Umbelliferae) and other species of Dorema growing in Persia and neighboring countries.

2. In roundish tears from 2 to $6 \mathrm{~mm}$. or more in diameter, externally pale, yellowish brown, internally milk white, brittle when cold and breaking with a flat conchoidal and waxy fracture; or the tears are superficially united into irregular masses without any intervening dark colored substance. Odor peculiar, taste bitter, acrid and aromatic. It softens on warming without completely melting. Partly soluble in water and alcohol.

3. On boiling with 10 parts water it forms a turbid liquid which is colored a dirty violet by ferric chloride $T$. $S$.

4. On fusing with alkali it yields resorcin.

5. On complete extraction with boiling alcohol, filtering, and drying the residue at $100^{\circ}$ C., not more than 40 percent. of insoluble matter should remain. The ash should not amount to over $7.5 \%$ and moisture $2.5-12 \%$.

6. If five grams finely broken, be boiled for one-fourth hour with $15 \mathrm{Cc}$. hydrochloric acid and filtered, the clear filtrate should not become fluorescent on adding excess of ammonia water (absence of galbanum and gum resin of Ferula tingitana or African ammoniacum).

\section{AMMONII ICHTHYOSULPHONAS.}

Ammonium Ichthyosulphonate.

1. Ammonium ichthyosulphonate is an aqueous solution, the solids of which consist largely of the ammonium salts of sulphonic acids, which latter have been prepared by sulphonating the tar-like distillate obtained from certain bituminous shales which contain the fossil remain of fishes.

2. Ammonium ichthyosulphonate is a reddish-brown to brown-black, syrupy liquid having a characteristic empyreumatic odor and burning taste.

3. It should be completely soluble in water; incompletely soluble in alcohol or ether but nearly soluble in a mixture of equal volumes of alcohol and ether; also soluble in a mixture of equal volumes of alcohol, water and ether. It is miscible with glycerin, oils and fats.

4. The aqueous solution of ammonium ichthyosulphonate (1-10) has a faintly acid reaction upon blue litmus paper.

5. The aqueous solution of ammonium ichthyosulphonate (1-10) yields a greenishblack, resin-like precipitate upon the addition of hydrochloric acid. This precipitate is nearly insoluble in ether; it is partially soluble in alcohol; soluble in water but if dissolved in the latter solvent it may again be precipitated from solution by the addition of hydrochloric acid.

6. With barium chloride $T$. S. the aqueous solution of ammonium ichthyosulphonate (1-10) gives a brownish-black precipitate 
which is insoluble in diluted hydrochloric acid.

7. If the aqueous solution (1-10) be boiled with potassium hydroxide $\mathrm{T}$. $\mathrm{S}$. ammonia should be evolved.

8. Ammonium ichthyosulphonate is incompatible with acid and saline solutions, fixed alkalies, their carbonates and iodides, alkaloidal salts and mercuric chloride.

9. If $1 \mathrm{Gm}$. of ammonium ichthyosulphonate be ignited it should leave not more than $0.001 \mathrm{Gm}$. of residue. If $10 \mathrm{Gm}$. of ammonium ichthyosulphonate be diluted with $90 \mathrm{Cc}$. of water, the mixture placed in a glass-stoppered cylinder and allowed to remain undisturbed for 24 hours, no deposit should form.

10. If dried at $100^{\circ} \mathrm{C}$. $\left(212^{\circ} \mathrm{F}\right.$. $)$ ammonium ichthyosulphonate should not lose more than 47.0 percent. of its weight (absence of an undue amount of water).

11. If from $5 \mathrm{Gm}$. to $6 \mathrm{Gm}$. of ammonium ichthyosulphonate be weighed into a flask, 25 Cc. of potassium hydroxide T. S. and $100 \mathrm{Cc}$. of water added, the mixture distilled until no more ammonia passes over, the distillate collected in $15 \mathrm{Cc}$. of normal sulphuric acid V. S. to which 1 drop of methyl orange T.S. has been added, and the excess of acid then titrated with tenth-normal potassium hydroxide, V. S., the amount of normal sulphuric acid consumed should correspond to from 2.9 percent. to 3.4 percent. of total ammonia $\left(\mathrm{NH}_{3}\right)$.

12. If from $5 \mathrm{Gm}$. to $6 \mathrm{Gm}$. of ammonium ichthyosulphonate be weighed into a beaker, diluted with $50 \mathrm{Cc}$. of water, $10 \mathrm{Cc}$. of a 10 percent. solution of albumen added, followed by 5 portions of $5 \mathrm{Cc}$. each of diluted hydrochloric acid, shaking after each addition, the mixture made up to a volume of $500 \mathrm{Cc}$. and filtered through a dry filter, and if $200 \mathrm{Cc}$. of the filtrate be heated to boiling, $10 \mathrm{Cc}$. of barium chloride $T$. S. added, the mixture allowed to stand for 24 hours, the precipitate of barium sulphate collected, ignited and weighed in the usual way, the weight of barium sulphate obtained should correspond to from 5.7 percent. to 6.2 percent. of ammonium sulphate.

13. If from $0.5 \mathrm{Gm}$. to $1 \mathrm{Gm}$. of ammonium ichthyosulphonate be weighed into a Kjeldahl flask, diluted with $20 \mathrm{Cc}$. of water, $5 \mathrm{Gm}$. of potassium chlorate added, followed by $30 \mathrm{Cc}$. of nitric acid, the mixture evaporated to about 5 Cc., 25 Cc. of hydrochloric acid added, this solution evaporated to about 5
Cc., $25 \mathrm{Cc}$. of hydrochloric acid again added, this solution evaporated to about $5 \mathrm{Cc}$., 100 Cc. of water added, the solution heated to boiling, $10 \mathrm{Cc}$. of barium chloride T. S. added, the mixture allowed to stand for 24 hours, the precipitate of barium sulphate collected, heated and weighed in the usual way, the weight of barium sulphate should correspond to at least 10 percent. of total sulphur.

14. If the ammonia contained in the ammonium sulphate as previously determined in ammonium ichthyosulphonate be calculated, and the result subtracted from the "total ammonia" as previously determined, the remainder should represent the ammonia combined with the "organic sulphuric acids." If this value be multiplied by 1.88 the result should represent the sulphur present in the sulphonic acids in an oxidized state, i. e., "sulphonic sulphur."

15. If the sulphur contained in the ammonium sulphate as previously determined in ammonium ichthyosulphonate be calculated, and the result subtracted from the "total sulphur" as previously determined, the remainder should represent the sulphur present in the organic-sulphonic acids contained in the substance.

16. If the "sulphonic" sulphur in ammonium ichthyosulphonate as previously calculated be subtracted from the sulphur in the organic sulphonic as previously calculated, the remainder should correspond to at least 5.5 percent. of "organic" ("sulphidic") sulphur.

\section{AMMONII PHOSPHAS.}

Ammonium Phosphate.

1. A mixture, in somewhat varying proportions, of diammonium hydrogen phosphate $\left[\left(\mathrm{NH}_{4}\right)_{2} \mathrm{HPO}=132.13\right]$ and ammonium dihydrogen phosphate $\left[\mathrm{NH}_{4} \mathrm{H}_{2} \mathrm{PO}_{4}=\right.$ 115.09]. It should contain not less than 98 percent. of these two salts and not less than 20 percent. of combined ammonia $\left(\mathrm{NH}_{3}\right)$. It should be kept in well-stoppered bottles in a cool place.

2. Colorless crystals, or a white crystalline powder, which lose ammonia on exposure to the air.

3. Soluble in about 4 parts of water, insoluble in alcohol. The aqueous solution $(1: 20)$ is alkaline to litmus paper.

4. Separate portions of the aqueous solution $(1: 20)$ yield with magnesia T. S. a white precipitate, with silver nitrate T. S. a yellow 
precipitate, and upon warming with ammonium molybdate $T$. S. a yellow precipitate.

5. A clear solution should result on dissolving $1 \mathrm{Gm}$. in $20 \mathrm{Cc}$. of water (limit of calcium, aluminum, etc.).

6. The aqueous solution $(1: 20)$ should not respond to the U. S. P. VIII Time Limit Test for heavy metals.

7. If $5 \mathrm{Cc}$. of the aqueous solution $(1: 20)$ be evaporated with $2 \mathrm{Cc}$. of nitric acid to dryness on the water bath, the solution of the residue in $5 \mathrm{Cc}$. of water should not respond to the U. S. P. VIII Modified Gutzeit's Test for arsenic.

8. An aqueous solution of the salt ( 1 in 100) acidulated with nitric acid should not be rendered more than slightly opalescent by silver nitrate T. S. (Limit of chlorides).

9. Weigh about $0.2 \mathrm{Gm}$. of the salt, dissolve it in $25 \mathrm{Cc}$. of water in a $200 \mathrm{Cc}$. volumetric flask, and add $100 \mathrm{Cc}$. tenth-normal silver nitrate V. S. Shake thoroughly for a few minutes, then add zinc oxide (free from chloride) in small successive portions, shaking vigorously after each addition, until the mixture is no longer acid to litmus paper. Dilute the contents of the flask to $200 \mathrm{Cc}$. with water, mix thoroughly, and filter at once. Strongly acidulate with colorless nitric acid $100 \mathrm{C} c$. of the filtrate which represents one-half of the ammonium phosphate taken, and titrate the excess of silver nitrate with tenth-normal potassium sulphocyanate V. S., using ferric ammonium sulphate as indicator. Each Cc. of tenth-normal silver nitrate V. S. corresponds to $0.003269 \mathrm{Gm}$. of phosphoric acid $\left(\mathrm{H}_{3} \mathrm{PO}\right)$.

10. Dissolve about $1.5 \mathrm{Gm}$. of the salt accurately weighed, in about $300 \mathrm{Cc}$. of water, add about 50. Cc. of 25 percent. sodium hydroxide solution, and distill the liberated ammonia into an excess of normal hydrochloric acid solution. Titrate the excess of acid with normal sodium hydroxide V. S., and calculate the percentage of ammonia $\left(\mathrm{NH}_{3}\right)$. The combined percentages of ammonia and of phosphoric acid found should represent not less than 98 percent. of ammonium phosphates.

\section{ANTIMONIUM SULPHURATUM.}

Sulphurated Antimony.

(Antimonium Oxysulphuratum Rubrum. Kermes Mineral.)

1. Chiefly antimony trisulphide $\left[\mathrm{Sb}_{2} \mathrm{~S}_{\mathbf{z}}=\right.$ 336.2] with small quantities of antimony tri- oxide, sodium pyroantimonate, and free sulphur. It should contain not less than $\mathbf{4 5}$ percent of antimony. as determined by the method given below. It should be kept in well-stoppered bottles, protected from light.

2. A red-brown powder, becoming lighter in color on exposure to light, odorless and tasteless. Insoluble in water and in alcohol. One $\mathrm{Gm}$. on warming with $10 \mathrm{Cc}$. of hydrochloric acid dissolves with the evolution of hydrogen sulphide, leaving a small residue composed chiefly of sulphur. The hydrochloric acid solution, after removal of hydrogen sulphide by heating the solution, yields a white precipitate when greatly diluted with water; the liquid separated from this precipitate yields an orange-red precipitate with hydrogen sulphide.

3. After shaking about $1 \mathrm{Gm}$. of Sulphurated Antimony with $20 \mathrm{Cc}$. of water, the filtered liquid should be neutral to litmus, remain clear on the addition of ammonium oxalate, and not become more than slightly turbid on the addition of barium chloride.

4. Boil $1 \mathrm{Gm}$. of Sulphurated Antimony with $100 \mathrm{Cc}$. of water until the volume is reduced to about $10 \mathrm{Cc}$. filter, and wash the residue thoroughly with water. The combined filtrate and washings, after evaporation to about $1 \mathrm{Cc}$., should not respond to Bettendorf's test for arsenic (U. S. P. VIII).

5. If about $1 \mathrm{Gm}$. Sulphurated Antimony accurately weighed be mixed with $20 \mathrm{Cc}$. of hydrochloric acid and a clear solution of 5 $\mathrm{Gm}$. tartaric acid in $20 \mathrm{Cc}$. of water, the mixture heated on a water-bath until the vapors no longer blacken lead acetate test paper and filtered and the residue washed until the washings are neutral to litmus and dried at $100^{\circ} \mathrm{C}$. the weight of this residue should not exceed 4 percent., and it should burn with the odor of sulphur dioxide, leaving not more than 0.2 percent. of ash.

6. Dilute the combined filtrate and washings from the preceding test to $100 \mathrm{Cc}$. Neultralize $25 \mathrm{Cc}$. of the solution with sodium carbonate, add $25 \mathrm{Cc}$. of a cold saturated solution of sodium bicarbonate, and at once titrate with tenth-normal iodine V. S., using starch solution as indicator. Each $\mathrm{Cc}$. of the tenth-normal iodine solution corresponds to $000504 \mathrm{Gm}$. of Antimony ( $\mathrm{Sb}$.).

\section{ARALIA RACEMOSA.}

American Spikenard. (Spignet.)

1. The dried rhizome and roots of Aralia 
racemosa Linné (Fam. Araliaceae), with not more than 5 percent. of adhering stem bases.

2. Rhizome of oblique growth, about 12 $\mathrm{cm}$. long and $5 \mathrm{~cm}$. thick, somewhat flattened, tortuous, pale-brown, somewhat annulately roughened, of fibrous fracture, frequently cut longitudinally, whitish internally; nodes approximate, each with a prominent stem about $3 \mathrm{~cm}$. broad; roots numerous, of various lengths, from 5 to $25 \mathrm{~mm}$. thick, usually cut longitudinally and furrowed, sometimes with transverse ridges and corky patches, lightbrown or purplish-brown externally, whitish and spongy or porous internally; fracture of the cortex short, of the wood short and fibrous; odor aromatic, taste mucilaginous, pungent and slightly acid.

3. A transverse section of the root examined microscopically shows a thick bark with several zones of secretion reservoirs containing oil, a well-developed cork with one or more hypodermal layers of lignified cells, and a more or less distinctly radiate wood.

4. A microscopic examination of the powdered drug reveals spherical or angular single or two or more compound starch grains from 5 to 20 microns in diameter, rosette aggregates of calcium oxalate from 30 to 70 microns in diameter, trachex with scalariform or reticulate thickenings and simple or bordered pores, characteristic lignified cells from the hypodermis about 40 to 100 microns long and about one-half as broad, their walls showing simple pores. (Distinction from Aralia nudicaulis.)

5. When incinerated, it should yield not more than 10 percent. of ash.

\section{ASARUM.}

Canada Snake-root (Wild Ginger).

1. The dried rhizome of Asarum canadense Linné (Fam. Aristolochiaceae), with only an occasional leaf or flower present.

2. Of horizontal growth, occasionally branched, two-edged when young, quadrangular when older, finely striate, usually more or less twisted, 5 to $17 \mathrm{~cm}$. long and 2 to $4 \mathrm{~mm}$. thick; nodes enlarged with irregular scars from scales; dark-purplish-brown externally; fracture short, whitish internally, starchy or resinous; odor aromatic, non-irritating upon heating; taste pungent and bitter; attached roots few, 5 to $7 \mathrm{~cm}$. long and not over $1 \mathrm{~mm}$. thick, having from 4 to 6 radial fibrovascular bundles.

3. A transverse section of the rhizome ex- amined microscopically shows a thick bark with numerous oil cells, a wood with about 12 fibrovascular bundles and a large pith.

4. The powdered drug, examined microscopically shows simple or two to four compound starch grains 4 to 20 microns in diameter, and tracheæ with scalariform or reticulate thickenings, a few spiral.

5. When incinerated the drug should yield not more than 12 percent. of ash.

\section{BARII PEROXIDUM.}

\section{Barium Dioxide. (Barium Peroxide.)}

1. Commercial Barium Dioxide, containing not less than 20 percent. $\left(\mathrm{BaO}_{2}=\mathbf{1 6 9 . 3 9}\right)$. It should be kept in well-closed vessels.

2. A heavy, grayish white or yellowish white powder, almost insoluble in water, with which it forms a hydrate having an alkaline reaction. Readily decomposed by diluted mineral acids with the production of hydrogen dioxide and the corresponding barium salt.

3. When heated to a bright red heat, Barium Dioxide fuses, loses oxygen, and is reduced to barium oxide.

4. A solution of $0.1 \mathrm{Gm}$. of Barium Dioxide in $5 \mathrm{Cc}$. of diluted hydrochloric acid yields a heavy white precipitate upon the addition of a few drops of diluted sulphuric acid (presence of barium).

5. Dissolve about $0.2 \mathrm{Gm}$. Barium Dioxide in $25 \mathrm{Cc}$. of water by the addition of $25 \mathrm{Cc}$. of diluted hydrochloric acid ( 1 in 5 ). Then add gradually from a burette tenth-normal potassium permanganate $V$. S. until a permanent pink color remains after agitation. Multiply the number of Cc. of tenth-normal potassium permanganate $V$. S. consumed by .00847 and divide the product by the weight of barium dioxide taken; the result, multiplied by 100 represents the percentage of pure barium dioxide present.

\section{DRIED BLOOD ALBUMIN.}

Serum Albumin.

1. The dried serum of the blood of domestic animals, prepared by desiccation at a low temperature.

2. Yellow to brownish amber transparent or translucent hard and brittle scales or fragments; taste slightly saline; odor not more than that characteristic of bloud; on igniting it emits an odor of burned animal matter.

3. It is insoluble in alcohol, chloroform or ether. Slowly and almost completely soluble 
in water; the aqueous solution is lavogyrate, the angle of rotation varying from $50^{\circ}$ to $62^{\circ}$; on heating the solution the albumin is coagulated and precipitated.

4. Upon incineration it should yield not more than 10 percent. of ash containing iron.

5. The aqueous solution ( 1 in 10) responds to the following tests; it is not readily precipitated by hydrochloric acid and the precipitate redissolves in excess of acid; it is only slowly precipitated by alcohol in excess; on shaking with an equal volume of ether the solution remains clear, without coagulation. (Difference from Egg Albumin.)

\section{BRYONIA.}

\section{Bryony.}

1. The dried root of Bryonia alba Linné, or of Bryonia dioica, Jacq. (Fam. Cucurbitaceae.)

2. Occurs usually in circular or elliptical slices, obtained by cutting the root more or less transversely, slices about 1.5 to $10 \mathrm{~cm}$. broad and 3 to $12 \mathrm{~mm}$. thick; the edges light gray or yellowish, rough and striate; the cut surface white or faintly yellow, showing a thin cortex and a wood with numerous projecting collateral fibro-vascular bundles arranged in concentric zones; fracture short and mealy, whitish internally; odor faint but distinct and characteristic; taste bitter and nauseous.

3. The powdered drug is light yellowish and when viewed with the microscope shows single rounded or two or more compound starch grains about 4 to 24 microns in diameter, frequently with a central cleft, trachex 35 to 60 microns wide reticulate or with bordered pores, and large yellow cork cells.

4. Upon the addition of sulphuric acid the powdered drug turns first reddish-brown and then purplish.

5. The drug should yield not more than 8 percent. of ash upon incineration.

\section{CALAMINA PREPARATA.}

Prepared Calamin. (Lapis Calaminaris.)

1. Native zinc carbonate containing a varying amount of zinc silicate, calcined at a moderate temperature; or artificial calcined zinc carbonate containing a small amount of ferric oxide.

2. A pinkish powder readily passing through a number 100 sieve, insoluble in water, soluble to a large extent in hydrochloric acid with some effervescence.
3. If $1 \mathrm{Gm}$. of prepared Calamin be digested for one hour on a water-bath with $25 \mathrm{Cc}$. of diluted hydrochloric acid, the loss by evaporation being replaced with water, the liquid filtered and the filtrate diluted to 100 Cc., $10 \mathrm{Cc}$. of this diluted filtrate, on addition of potassium iodide T. S., should show no precipitate within ten minutes (limit of lead) ; $10 \mathrm{Cc}$. portions of the diluted filtrate, when boiled with a few drops of nitric acid, then boiled with excess of ammonia water and filtered, should give (1) with hydrogen sulphide $\mathrm{T}$. S. an abundant white precipitate (presence of zinc); (2) with excess of hydrochloric acid followed by potassium ferrocyanide T. S. an abundant yellowish-white precipitate (presence of zinc); (3) when diluted with 4 parts of water, slightly acidulated with acetic acid and treated with ammonium oxalate T. S., not more than a slight turbidity (limit of calcium); and (4) when slightly acidulated with hydrochloric acid, and treated with a few cubic centimeters of potassium sulphate T. S., should show not more than a slight turbidity at once (limit of soluble barium salts).

4. The residue insoluble in diluted hydrochloric acid obtained from $1 \mathrm{Gm}$. of prepared calamin, is fused with 5 parts of anhydrous scdium carbonate, the fused mass treated with water, the mixture filtered and washed, the insoluble portion dissolved in diluted hydrochloric acid and diluted to 100 Cc., $10 \mathrm{Cc}$. of this dilution should give no immediate turbidity with $2 \mathrm{Cc}$. of potassium sulphate T. S. (absence of barium sulphate).

\section{CARMINUM.}

\section{Carmin.}

1. The aluminum lake of the coloring obtained from cochineal. It should be kept in well-stoppered bottles, protected from light.

2. In irregular, angular, bright red masses or powder, without odor or taste. Upon burning, Carmin gives off the odor of burned feathers.

3. Insoluble in water, but completely soluble in ammonia water, forming a dark purplish solution.

4. On ignition, the ash obtained should not exceed 12 percent.

5. On fusing the ash with potassium cyanide, dissolving in concentrated hydrochloric acid and diluting with water, the solution should yield no precipitate with hydrogen 
sulphide, nor with sulphuric acid (absence of tin, lead and barium compounds).

\section{CASTANEA.}

Chestnut Leaves.

1. The dried leaves of Castanea dentata (Marsh.) Borkh. (Fam. Fagaceae), collected in September or October, while still green, with which may be admixed not more than 5 percent. of twigs or other impurities.

2. Petioles stout, about $12 \mathrm{~mm}$. long; blades entire or slightly broken and usually folded or matted together; about 15 to 25 $\mathrm{cm}$. long and $5 \mathrm{~cm}$. broad, oblong-lanceolate, the apex attenuate, acute at the base, coarsely and sharply serrate with ascending attenuate teeth, nearly smooth, coriaceous in texture, the upper surface dark green, the lower light green; distinctly pinnately veined, the veins of the first order diverging at angles of about $60^{\circ}$, each terminating in one of the teeth; odor slight; taste astringent.

3. The powdered drug under the microscope shows a few non-glandular hairs about .2 to $.5 \mathrm{~mm}$. long, nearly smooth, thickwalled, distinctly yellowish, occasionally in groups of three to eight and spreading from the base; numerous calcium oxalate crystals in rosette aggregates or in monoclinic prisms, 10 to 35 microns in diameter, occasionally in crystal fibers; parenchyma cells containing irregular yellowish-brown tannin masses which are colored blue with ammonioferric alum solution.

4. Upon incineration it should yield not more than 5 percent. of ash.

\section{COCILLANA.}

1. The dried bark of Guarea Rusbii (Britton) Rusby (Fam. Meliaceae).

2. In flat or curved pieces of variable size and from 3 to $25 \mathrm{~mm}$. thick; outer surface shallowly or deeply fissured, according to age and thickness, gray-brown, often ashy-gray from lichen growths, or of a deeper brown where the cork has been removed; inner surface of medium brown color, strongly and coarsely longitudinally striate, the striae straight or wavy; inner bark usually much thicker than the outer, its fracture coarse, splintery-fibrous; odor scarcely characteristic; taste slightly astringent, after chewing, peculiar and slightly nauseous.
COFFEA TOSTA.

\section{Roasted Coffee.}

1. The dried ripe seeds of Coffea Arabica (Linné) Coffea Liberica (Bull) (Fam. Rubiaceae) and other species of Coffea, roasted until they develop a brown or blackish color and characteristic aroma.

2. The roasted seeds are oval, of variable size, longitudinally grooved upon the flat side and showing traces of the papery endocarp in the cleft. The color varies from a light yellowish brown to almost black, according to the degree to which the roasting process has been carried. The roasted seeds have a characteristic aromatic odor and a pleasant bitter taste. On ignition, roasted coffee should leave not less than 3 nor more than 5 percent. of ash.

3. If one gram of Roasted Coffee in fine powder be percolated with Ether until exhausted and the ethereal percolate evaporated to dryness, the residue should weigh not less than 0.1 gram (presence of at least 10 percent. fat).

4. If one gram of roasted coffee be boiled with $10 \mathrm{Cc}$. of distilled water, filtered, the filtrate acidified with $1 \mathrm{Cc}$. dilute Sulphuric Acid and then decolorized by cautious addition of Potassium Permanganate T. S., the decolorized solution should show no blue coloration on addition of iodine T. S. (absence of starch).

5. If roasted coffee berries be shaken for one minute with cold water or alcohol and the berries removed by straining, the separated liquids should show no colored or heavy deposit nor should any color be imparted to the alcohol (absence of colored and mineral facings).

6. For pharmaceutical purposes, a coffee should be selected which has been roasted to a chestnut brown color and which when assayed by the process given under "Thea," yields not less than 1 percent. of caffeine.

(To be continued.)

\section{THE GIFT OF MAKING FRIENDS.}

"The man who hails you Tom or Jack, And proves by thumping on your back His sense of your great merit, Is such a friend that one had need, Be very much his friend indeed To pardon or to bear it."-Cozuper. 